cooperation with a designer and a medical expert. This was followed by a common group session. Finally, SE was performed based on semi-structured group and individual interviews with patients and disease-management stakeholders.

Results: The study included 9 rheumatoid arthritis (RA) patients, 4 psoriatic arthritis (PsA) patients, 1 ankylosing spondylitis (AS) patient, 2 doctors, 2 nurses, 1 medical secretary, and 4 key public servants involved in the disease management of the selected rheumatic diseases. Saturation was reached after $3 \mathrm{CM}$ patient workshops, generating 121 statements, which were organized by the participants into themes. Through content analysis of the results from the 3 workshops, 4 concepts were generated: technical usability, physical design, concerns, and enthusiasm. These data were used in the iterative PD sessions, resulting in 4 new proposed prototypes. Finally, SE demonstrated that the identified concepts were pivotal for both facilitating and hampering device implementation, thus creating value when introducing the new e-Device.

Figure: The Parker Model

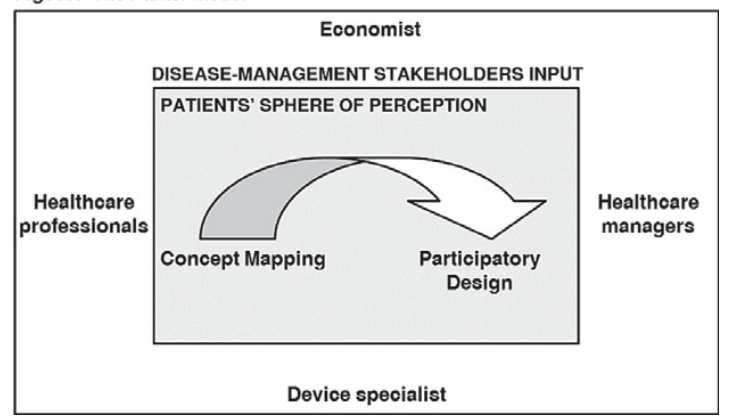

Conclusions: Patient participation in the 3-step qualitative Parker Model identified important aspects to consider when designing and implementing an innovative device for the treatment and management of RA, PSA, and AS. This is the first time a composite, qualitative research model has been applied when introducing a new device to support these disease areas. The responses from patients and disease-management stakeholders indicated that it is key to include patient input in the design and adaptation of devices alongside education and communication with stakeholders. These resources can help ensure added value when developing devices for the management of RA, PsA, and AS using biologic medicines.

Acknowledgements: This study was funded by UCB Pharma and the Oak Foundation. We thank the patients and their caregivers in addition to the investigators and their teams who contributed to this study. Editorial services were provided by Costello Medical Consulting.

Disclosure of Interest: T. Jørgensen Speakers bureau: Abbvie, Biogen, Novartis, Roche, UCB Pharma, L. Klokker: None declared, M. Skougaard: None declared, H. Asmussen Consultant for: The Parker Institute, UCB Pharma, A. Lee: None declared, I. Mountian Employee of: UCB Pharma, H. Gudbergsen: None declared, L. Kristensen Speakers bureau: AbbVie, Amgen, BMS, Celgene, Eli Lilly, Janssen Pharmaceuticals, MSD, Novartis, Pfizer, UCB Pharma DOI: 10.1136/annrheumdis-2017-eular.1770

\section{AB1114 PATIENT'S SELF-MONITORING OF DISEASE ACTIVITY OF RHEUMATIC DISEASES VIA WEBAPP - STUDY DESIGN, PATIENT'S PERSPECTIVE AND RECRUITMENT IN THE FIRST 11 MONTHS OF THE SWISS MULTICENTRE, LONGITUDINAL COMPASS II STUDY}

V.K. Jaeger ${ }^{1}$, P. Schiffer ${ }^{2}$, P. Zufferey ${ }^{3}$, L. Pichler ${ }^{1}$, A. Badaracco ${ }^{4}$, M. Walder ${ }^{5}$ ${ }^{\text {J. Dudler }}{ }^{6}$, D. Frey ${ }^{7}$, F. Müller ${ }^{1}$, U.A. Walker ${ }^{1} .{ }^{1}$ University Hospital Basel, Basel; ${ }^{2}$ Praxis beim Rathaus, Zofingen; ${ }^{3}$ Lausanne University Hospital, Lausanne; ${ }^{4}$ Studio Medico Badaracco Cattaneo, Lugano; ${ }^{5}$ Praxis Walder, Dübendorf; ${ }^{6}$ Hôpital Cantonal Fribourg, Fribourg; ${ }^{7}$ Praxis Frey, Basel, Switzerland

Background: The management of patients with rheumatic diseases is guided in part by asking patients about their medical history at each clinic visit. Patients often find it difficult to accurately remember the course of their symptoms between these appointments as they are often months apart. Regular app-based patients' self-monitoring of disease activity (with our without feedback to the rheumatologist) between clinic visits might provide a possible solution for this. The COmPASS I study [1] demonstrated that RA patients' self-assessments of disease activity via App correlate strongly with rheumatologists' assessments. Following up on this, the Swiss based COmPASS II study is embedded in the Swiss rheumatology registry (SCQM) and hence allows the linkage of data obtained via the COmPASS II App from the patients with routine clinical data collected in the registry.

The main aims of the COmPASS II study are to assess if continuous selfmonitoring of the disease by patients optimises disease management and outcome in rheumatic diseases, and to assess the fluctuation of disease activity between clinic visits.

Objectives: The objectives of this abstract are to describe the set-up and the recruitment of the COmPASS II study in the first 11 months.

Methods: The COmPASS II App questionnaire consists of the RAPID3 score, a validated, commonly used PRO to self-assess disease activity. Additionally, patients are asked about their therapy compliance and cortisone dose.

At inclusion, interested patients with RA, axSpA and PsA are electronically randomized into 3 study arms (Figure 1). In arm 1 patients and rheumatologist are displayed the self-assessed disease activity over time, the patient directly via the App and the rheumatologist via the SCQM registry. In arm 2 only the patients are displayed their disease activity chart and in study arm 3 neither sees the recorded data. Patients are encouraged to fill in the App weekly.

Results: The COmPASS II App went online on the 15/02/2016. In the first 11 months of COmPASS II, 272 patients were enrolled by their rheumatologist. $64 \%$ of patients used the WebApp (32\% in arm 1,38\% in arm 2 and $30 \%$ in arm 3); $82 \%$ of patients filled in the questionnaires for longer than a months, the longest follow-up was 11 months. On average patients use the App every 2 weeks. Patients found the App easy to use "The COmPASS II WebApp is so easy to use. It doesn't even take me 2 min." and received feedback included "Now my rheumatologist sees how I was since the last appointment instead of me trying to remember how I was half a year ago."

Figure 1. Design of the COmPASS II study.

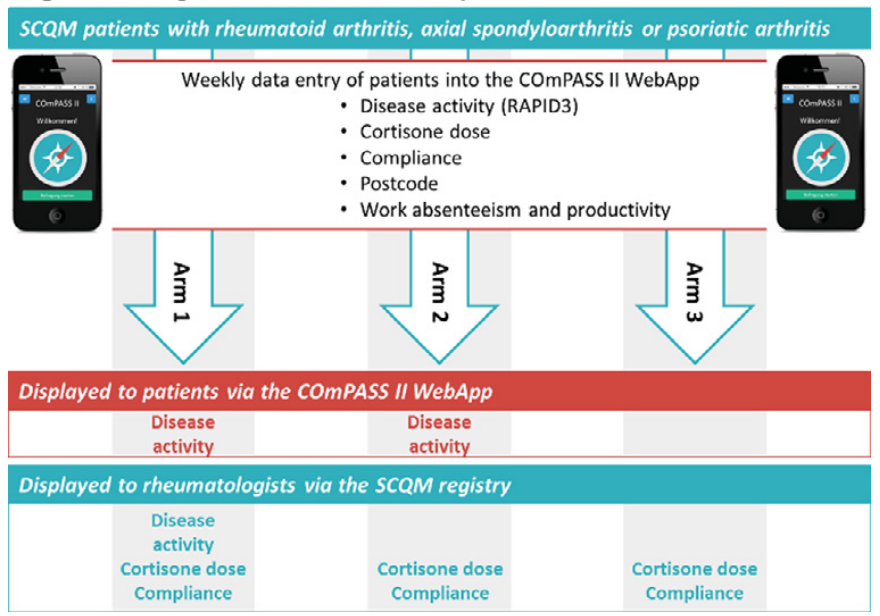

Conclusions: The COmPASS II study will validate the utility of app-based patients' self-assessments in enhancing disease control in a treat to target approach and deliver numerous additional scientific data.

References:

[1] Mueller R et al. Patient's Self-Monitoring Via Smartphone: The Compass Study - COrrelation between PAtient self-ASSessment of rheumatoid arthritis disease activity via smartphone technology and physicians' validated scores [abstract]. Arthritis Rheumatol. 2014;66(S10).

Acknowledgements: COmPASS II is supported by an unrestricted grant from AbbVie.

Disclosure of Interest: None declared

DOI: 10.1136/annrheumdis-2017-eular.3260

\section{AB1115 THE FEASIBILITY OF UTILIZATION OF MOBILE DEVICES TO ENHANCE PATIENT REPORTED OUTCOMES MEASURES (PROMS) IN RHEUMATOLOGY PRACTICE}

V. Ognenovski ${ }^{1}, 2$, K. Burger ${ }^{3}$, K. Weiss ${ }^{4}$, L. Esser ${ }^{4}$, D. Khanna ${ }^{1} .{ }^{1}$ Division of Rheumatology, University of Michigan, Ann Arbor, United States; ${ }^{2}$ Rheumatology Clinic, Ss Cyril and Methodius Faculty of Medicine, Skopje, Macedonia, The Former Yugoslav Republic Of; ${ }^{3}$ Information Technology; ${ }^{4}$ University of Michigan, Ann Arbor, United States

Background: Patient reported outcome measures (PROMs) are accepted modalities of gathering patient-reported health status such as physical, mental and social well-being. In addition to research applications, in some countries such as the United States, some of these measures are being considered as metrics for quality of care. The advent and wide spread use of the electronic medical record (EMR) in the United States has enabled providers (and patients) to collect PROMs electronically via patient portals (1).

At the University of Michigan, the patient medical record is maintained by MiChart- an EPIC ${ }^{\circledR}$ software which interfaces with the Patient Reported Outcomes Measures System -PROMIS (2)- an NIH funded project for development of assessment tools for collecting and analyzing patient health status. Our initial effort focused on integrating the PROMIS questionnaires into the patient EMR for two domains: Adult Physical Function and Pain Intensity Scores into patient portals (electronic patient-physician communication tool), thus enabling patient to complete questionnaires from home computers. Our collection rate of completed PROMs questionnaires via patient portals was about $5-10 \%$.

Objectives: The aim of our project was to examine/enhance collection rate of PROMs with the utilization of portable devices /tablet based PROMs at the time of check-in the clinic by the patient. 